\section{P1-462 TRAFFIC ACCIDENT MORTALITY: TRENDS, REGIONAL DIFFERENCES AND SPATIAL DISTRIBUTION IN A NORTH- EASTERN STATE IN BRAZIL}

doi:10.1136/jech.2011.142976g.51

${ }^{1} \mathrm{M}$ L Lima, ${ }^{*}$ A P Almeida, ${ }^{1} \mathrm{E}$ Cesse, ${ }^{1} \mathrm{G}$ Tadeu, ${ }^{1} \mathrm{P}$ Nobre. ${ }^{1}$ Centro de Pesquisas Aggeu Magalhães, Recife, Pernambuco, Nordeste, Brazil; ${ }^{2}$ Secretaria Saude Estado de Pernambuco, Recife, Pernambuco, Nordeste, Brazil

This study examined changes in traffic accident mortality, examining different types of victims according to each development region in the state of Pernambuco, and estimated expected years of life lost. A descriptive and ecological study was carried out, using secondary data describing traffic collision deaths from the Ministry of Health Mortality Information System, from 1998 through 2007. Spatial analysis techniques were used: Mortality Coefficient Estimates by the Local Empiric Bayesian Method and Moran Spreading Diagram, applied over the digital cartographic databases from Pernambuco. Percentage variation in the coefficient showed a $16.3 \%$ decline between the first and the last years in the series. Linear regression showed a negative trend and was statistically significant at the $5 \%$ level. The observed decline in traffic collisions resulted mainly from a $35.3 \%$ reduction in pedestrian mortality rates, although all the other types of accidents contributed to this decrease, except for motorcycle mortality, which saw an increase of $297 \%$. From the 185 municipalities, 16 encompassing five clusters were identified with an average mortality rate ranging from 5.66 to 11.66 per 100000 inhabitants, were considered critical areas. Three clusters were located in the area known as Sertão and two in the Agreste of the state. These results point to a greater risk of dying due to motorcycle accidents outside of the Metropolitan areas, and within the identified ones. This suggests that intervention measures that take into consideration the economic, social and cultural contexts are critical.

\section{P1-463 HPV VACCINATION: KNOWLEDGE, PRACTICE AND BEHAVIOURAL INTENTIONS ABOUT PREVENTION OF CERVICAL CANCER AND STDS IN FRENCH GIRLS}

doi:10.1136/jech.2011.142976g.52

${ }^{1} \mathrm{D}$ Lutringer-Magnin,* ${ }^{2} \mathrm{~J}$ Kalecinski, ${ }^{1} \mathrm{G}$ Barone, ${ }^{2} \mathrm{~V}$ Régnier, ${ }^{3} \mathrm{Y}$ Leocmach, ${ }^{3} \mathrm{~B}$ Soubeyrand, ${ }^{1} \mathrm{~J}$ Haesebaert, ${ }^{4} \mathrm{P}$ Vanhems, ${ }^{2} \mathrm{~F}$ Chauvin, ${ }^{1} \mathrm{C}$ Lasset. ${ }^{1}$ Université Lyon 1 , CNRS UMR 5558 and Centre Léon Bérard, Lyon, France, ${ }^{2}$ Institut de Cancérologie de la Loire and Université Jean Monnet de Saint-Étienne, Saint-etienne, France; ${ }^{3}$ SanofiPasteur MSD, Lyon, France; ${ }^{4}$ Université Lyon 1, CNRS UMR 5558 and Hospices Civils de Lyon, Lyon, France

Objectives To examine knowledge about HPV vaccination and behaviour towards STD among 14-23-year-old (yo) girls and determine the correlation with HPV vaccination status.

Methods From 11/2008 to 04/2009, 316 girls were recruited by general practitioners in a cross-sectional study and filled a selfadministered questionnaire. Twenty-eight were interviewed by a sociologist.

Results Of the 316 girls, HPV vaccination was reported by 135 $(42.7 \%)$. Parents were involved in the decision of vaccination for $62.4 \%$ of the 14-20 yo. Majority of unvaccinated girls preferred to wait $(34.2 \%)$, did not feel concerned $(27.3 \%)$ or intended to get the vaccine soon (25.5\%). During the interviews, the 10 vaccinated girls declared having the same opinion as their parents and uncertain girls thought they were not yet concerned. Knowledge of HPV and papsmear, need of pap-smear despite HPV vaccination was higher in vaccinated girls $(13.3 \%$ vs $5.5 \%$; $60.6 \%$ vs $34.9 \%$ in $14-16$ yo girls and $60 \%$ vs $25.6 \%$ in $21-23$ yo girls respectively). Overall, $87.2 \%$ cited condom for STD prevention and $88 \%$ of sexually active girls used it, irrespective of HPV vaccine status. Conditions for stopping condom use were more often reported by vaccinated $14-16$ yo girls ( $24.2 \%$ vs $11.1 \%)$

Conclusion Knowledge about CC prevention was poor but seemed higher among vaccinated girls. Knowledge and behaviours about STD prevention seemed appropriate, whatever the HPV vaccination status. HPV vaccination should be widely proposed to adolescents and their parents and information on it and on CC prevention should be reinforced.

\section{P1-464 INCIDENCE OF BREAST CANCER PATIENTS AT HIGH RISK OF BRCA GERMLINE MUTATION AT THE NATIONAL CANCER INSTITUTE OF BRAZIL}

doi:10.1136/jech.2011.142976g.53

V Machado, ${ }^{*}$ L Almeida. National Cancer Institute, Rio de Janeiro, Brazil

Introduction Hereditary breast cancer accounts for $5 \%$ to $10 \%$ of all cases and the most frequently found germline mutation occur in tumour suppressor gene BRCA.

Methods To estimate the incidence of individuals with a high probability of carrying a mutation in BRCA1 or BRCA2 genes, a questionnaire with 13 questions was developed to screen individuals at a high risk of hereditary cancer among breast cancer patients at the National Cancer Institute of Brazil. This instrument was based on the criteria used by the National Comprehensive Cancer Network for the referral of patients with breast cancer for genetic counselling. Patients who answered yes to any of the questions were interviewed about their family history. The probability of BRCA gene mutation was determined by the statistical model BRCAPRO Results Among 118 patients who were interviewed with the screening questionnaire, $52(44.1 \%)$ answered yes to at least one question. Using a $>10 \%$ BRCA gene mutation probability threshold, $4.4 \%$ of breast cancer patients had a high risk of being carriers of a germline mutation of BRCA1 or BRCA2 genes. The greater the number of affirmative answers, the more likely the patient had a mutation $(\mathrm{r}=0.621 ; \mathrm{p}<0.001)$.

Conclusion A screening tool can easily identify which patients should be referred for genetic counselling. The use of probability models can assist in building and adapting these questionnaires.

\section{P1-465 EDUCATION AND CARDIOVASCULAR DISEASE INCIDENCE IN DANISH MEN AND WOMEN. A DISCORDANT TWIN PAIR DESIGN}

doi:10.1136/jech.2011.142976g.54

${ }^{1,2} \mathrm{M}$ Madsen, ${ }^{*}{ }^{3} \mathrm{P} \mathrm{K}$ Andersen, ${ }^{1} \mathrm{M}$ Gerster, ${ }^{3} \mathrm{~A} \mathrm{M}$ N Andersen, ${ }^{1,4} \mathrm{~K}$ Christensen ${ }^{2,5} \mathrm{M}$ Osler. ${ }^{1}$ University of Southern Denmark, Odense, Denmark; ${ }^{2}$ Danish Ageing Research Center, Odense, Denmark; ${ }^{3}$ University of Copenhagen, Copenhagen, Denmark; ${ }^{4}$ The Danish Twin Registry, Odense, Denmark; ${ }^{5}$ Glostrup University Hospital, Glostrup, Denmark

Introduction Social inequality in cardiovascular disease (CVD) is well-established. However, the causal paths driving this association are unclear. To disentangle the effect of education from underlying background factors we investigated the association between education and the risk of CVD using twin data to adjust for familial confounding.

Methods The study was based on data from the Danish Twin Registry linked to official registers in Statistics Denmark, including the National Inpatient Registry and Causes of Death Registry. A total of 12240 monozygotic (MZ) and 20822 dizygotic same sexed (DZSS) twins were analysed. Unpaired and intrapair analyses were compared. 
Results In the unpaired analyses, an inverse educational gradient in CVD risk was observed, particularly in women. This association was not replicated in the intrapair analyses of female $M Z$ twins, but it persisted among female DZSS twins. For men, the pattern was less clear.

Conclusions The attenuation of association in the intrapair analyses suggest that shared familial factors account for part of the observed association between education and CVD. The fact that it was primarily attenuated in $\mathrm{MZ}$ twins may point to genetic factors as an important source of confounding. However, since education was associated with CVD in the intrapair analysis of DZSS twins, there was still some evidence of effect of education. Finally, these Danish data suggest that the social inequality in CVD is larger for women than for men.

\section{P1-466 EFFECTS OF OUTDOOR TEMPERATURE AND RAIN ON THE RISK OF HEMORRHAGIC STROKE}

doi:10.1136/jech.2011.142976g.55

${ }^{1} \mathrm{R}$ Magalhães, ${ }^{*}$ 1,2 $\mathrm{M}$ Correia, ${ }^{1} \mathrm{M} \mathrm{C}$ Silva. ${ }^{1}$ Instituto Ciências Biomédicas de Abel Salazar, Universidade do Porto, Porto, Portugal, ${ }^{2}$ Centro Hospitalar do Porto, Hospital Santo António, Porto, Portugal

Introduction Changes in meteorological parameters have been associated with stroke occurrence. The incidence of primary intracerebral haemorrhages (PICH) seems to increase in days with cold/ mild outdoor temperature. In Portugal, neurologists forward the hypothesis that the incidence of $\mathrm{PICH}$ increases in rainy days and not particularly low temperatures. This study aims to study the association between occurrence of $\mathrm{PICH}$ and weather parameters.

Methods Data from ACINrpc-project, involving 78 patients suffering a first-ever-in-the-lifetime PICH over a 2-year period in the city of Porto was used. Information on daily weather parameters was obtained from the National Meteorological Office. A Poisson model was used to estimate the association between weather parameters and PICH incidence. Using a conditional logistic regression model, a case-crossover design was then used to estimate the risk of PICH following specific exposures associated with PICH incidence: low diurnal temperature range (DTR) and rainy days. For each subject, the case period was matched with 4 control periods, the same weekday in the previous 4 weeks.

Results PICH incidence increases by $11.8 \%$ (95\% CI 3.8 to $20.4 \%$ ) for $1{ }^{\circ} \mathrm{C}$ drop in DTR and $3.1 \%$ (95\% CI 1.1 to $5.1 \%$ ) for a $1 \mathrm{~mm} / \mathrm{m}^{2}$ in precipitation. Following a day with a $\mathrm{DTR}<4^{\circ} \mathrm{C}$ the $\mathrm{OR}$ is 2.9 (95\% CI 1.4 to 5.8 ), increasing to 8.8 (95\% CI 1.7 to 44.8 ) after a $48 \mathrm{~h}$ exposure. Following days with low DTR and rain, the OR is 3.2 (95\% CI 1.3 to 8.1 ) and 9.5 (95\% CI 1.1 to 88.9$)$ for a precipitation $>10 \mathrm{~mm} / \mathrm{m}^{2}$ and $40 \mathrm{~mm} / \mathrm{m}^{2}$, respectively.

Conclusion Precipitation by itself is not associated with PICH incidence, nevertheless has a synergistic effect in low DTR days.

\section{P1-467 SERO-PREVALENCE OF RIFT VALLEY FEVER IN SOUTHWESTERN SAUDI ARABIA}

doi:10.1136/jech.2011.142976g.56

T Al-Azraqi, A E Mekki, A Mahfouz. ${ }^{*}$ College of Medicine, King Khalid University, Abha, Saudi Arabia

Introduction The objective was to study seroepidemiology and potential risk factors of Rift Valley Fever (RVF) virus infection in South Western Saudi Arabia.

Methods A random sample of the general population were studied. Through questionnaire interviews, data were collected regarding sociodemographic status, housing conditions, animal contact and other relevant information. Blood samples were taken and tested for
RVF-specific IgG and IgM utilising enzyme-linked immunosorbent assays (ELISAs).

Results Out of 2322 persons included in the study, only 139 were positive for RVF-specific IgG giving an overall prevalence of $6.0 \%$. On the other hand, none of the study samples were found to be sero-positive to RVF-specific IgM. The highest prevalence of sero positive RVF IgG was observed in Al Birk of Aseer region (13.3\%) followed by Al-Arda of Jizan Region (11.8\%), where the first animal deaths were reported during 2000-2001 outbreak. The study revealed zero prevalence of specific IgM and IgG among children born after the 2000-2001 outbreak. Using multivariate binary logistic regression analysis, the following significant risk factors were identified; lacking house electricity, having animals in the house, history of slaughtering animals, contact with or transporting aborted animals.

Conclusion The lack of recent virus activity mandates the rigorous maintenance of the control measures undertaken by the Ministries of Agriculture and Health. It is recommended to have regular seroepidemiological surveillance of RVF among humans, fostering public health messages in the region for risk reduction on reducing the risk of animal-to-human transmission as a result of unsafe animal husbandry and slaughtering practices.

\section{P1-468 TOWARDS A MODE OF COLLECTIVE CONSTRUCTION OF EPIDEMIOLOGICAL KNOWLEDGE}

doi:10.1136/jech.2011.142976g.57

${ }^{1} \mathrm{~B}$ Mariana, ${ }^{* 1} \mathrm{M}$ A Lia, ${ }^{1} \mathrm{H}$ Juliana, ${ }^{2} \mathrm{~A}$ M Franci. ${ }^{1}$ Universidad Nacional de Córdoba, Córdoba, Argentina; ${ }^{2}$ Universidad Nacional de Villa María, Córdoba, Argentina

Several Latin-American authors (Breilh, Almeida Filho, Czeresnia, among others) and some Europeans (as Tognoni) argue critically about the ways of constructing knowledge in epidemiology. They coincide in pointing out the limitation of the expert eye to account for the processes collective health. They debate how to manage knowledge and mechanisms to coordinate the management of institutional knowledge to the collective management of knowledge, in order to generate conceptual and methodological tools to impact effectively on the life stage of communities. We hypothesise that comanagement of knowledge, as inter-subjective process between academics and communities, promotes the transforming and democratising actions. In this regard, two national universities in the province of Cordoba, along with a local institution of healthcare built since 2008 an area of informal training, the Permanent Seminar of Epidemiology Community (EC), whose line of work is health as indicator of life, autonomy, knowledge and democracy in the communities. Participants are workers and health promoters from different districts of the province, members of community-based organizations and universities (students and teachers). In this context, it has been done during 2009-2010 a province-wide survey of experiences in community health, encouraging integration of community members to the $\mathrm{EC}$ research network. The progress made in terms of health monitoring and community organising around health is the subject of a manual about EC co-management of knowledge, and realises the real possibilities of achieving them.

\section{P1-469 SOCIOECONOMIC STATUS OF INJURED CHILDREN IN ZANJAN, IRAN}

doi:10.1136/jech.2011.142976g.58

S Mazloomzadeh, ${ }^{*}$ M Hasaniha. Zanjan University of Medical Sciences, Zanjan, Iran

Introduction Injuries are one of public health priorities in Iran Information on injuries in children and its related factors are less well known. The aim of this study was to describe the socioeconomic factors in injured children in Zanjan, Iran. 